\title{
Employment of an Extended Double-Integrating-Sphere System to Investigate Thermo-optical Material Properties for Powder Bed Fusion
}

\author{
Thomas Schuffenhauer, Thomas Stichel, and Michael Schmidt
}

Submitted: 18 December 2020 / Revised: 29 January 2021 / Accepted: 12 February 2021 / Published online: 5 March 2021

\begin{abstract}
The optical energy input during laser-based powder bed fusion of polymers (PBF-LB/P) is influenced by a variety of process parameters (e.g., energy density) and powder material properties (e.g. optical properties, additives). Qualification of newly developed and/or modified powder materials still requires extensive, empirical parameter studies to assess processibility and find suitable process strategies. For powder characterization, a double-integrating-sphere system with an intervening hot stage, which allows accurate sample heating during the measurement of the optical properties, is presented and described. For qualification of the system and the associated characterization method for the PBF-LB/P process, the interaction of a collimated $\mathrm{CO}_{2}$ laser beam with selected polyamide powder materials during heating and cooling is investigated. The obtained results illustrate the suitability of the presented thermo-optical characterization technique, i.e., the temperature-dependent measurement of radiation reflected by and transmitted through the samples, for the systematical investigation of material-related (i.e., additives) and process-related (i.e., preheating temperature, layer height) influences on the beam-matter interaction.
\end{abstract}

Keywords integrating sphere, material characterization, optical properties, polymer, powder bed fusion

\section{Introduction and Motivation}

In laser-based powder bed fusion of polymers (PBF-LB/P), also known as laser sintering, a thermoplastic powder material is globally preheated before a scanning $\mathrm{CO}_{2}$ laser beam irradiates and melts the powder locally. This is repeated for each layer until the part is completed, followed by a cooling phase. The mentioned energy deposition steps (i.e., preheating by infrared emitters and selective melting by laser irradiation) significantly influence the PBF-LB/P process and the resulting

This invited article is part of a special topical focus in the Journal of Materials Engineering and Performance on Additive Manufacturing. The issue was organized by Dr. William Frazier, Pilgrim Consulting, LLC; Mr. Rick Russell, NASA; Dr. Yan Lu, NIST; Dr. Brandon D. Ribic, America Makes; and Caroline Vail, NSWC Carderock.

Thomas Schuffenhauer, Bayerisches Laserzentrum GmbH, 91052 Erlangen, Germany; Collaborative Research Center (CRC) 814 "Additive Manufacturing", 91052 Erlangen, Germany; and Erlangen Graduate School in Advanced Optical Technologies (SAOT), 91052 Erlangen, Germany; Thomas Stichel, Bayerisches Laserzentrum $\mathrm{GmbH}$, 91052 Erlangen, Germany; and Collaborative Research Center (CRC) 814 "Additive Manufacturing", 91052 Erlangen, Germany; and Michael Schmidt, Bayerisches Laserzentrum GmbH, 91052 Erlangen, Germany; Institute of Photonic Technologies (LPT), Friedrich-Alexander-University Erlangen-Nuremberg, 91052 Erlangen, Germany; Collaborative Research Center (CRC) 814 "Additive Manufacturing", 91052 Erlangen, Germany; and Erlangen Graduate School in Advanced Optical Technologies (SAOT), 91052 Erlangen, Germany. Contact e-mail: t.schuffenhauer@blz.org. part properties (Ref 1). In turn, the beam-matter interaction is influenced by a multitude of factors ranging from material properties (e.g., chemical composition of the base material, bulk powder properties such as bed density, additives) to process parameters (e.g., preheating temperature, powder layer height, energy density, scanning strategy) (Ref 2,3).

Radiation incident on the powder bed surface is either reflected, transmitted into deeper layers, or absorbed by the polymer particles (Ref 4). In PBF-LB/P, a certain penetration depth of the laser beam is desirable to establish adhesion between the single layers, while the main amount should be absorbed in a precisely defined top layer of the powder bed and reflective losses should be minimized. For enhanced part properties (e.g., mechanical properties and resolution along the building direction) adequate energy deposition is crucial, which in turn requires the different interaction mechanisms to be fully understood (Ref 5).

Despite their significance to the process behavior and the resulting part properties, the optical properties of feed stock for powder-based additive manufacturing (AM) have generally been investigated rarely. In the field of $\mathrm{PBF}-\mathrm{LB} / \mathrm{P}$, few publications employ optical characterization approaches to gain insights into the beam-matter interaction during manufacturing. A comprehensive overview of experimental and simulation studies of the optical behavior of various materials can be found in the review by Kruth et al. (Ref 6). Tolochko et al. (Ref 2) analyzed the absorptance properties of various powder materials at two different wavelengths $(1.06 \mu \mathrm{m}$ and $10.6 \mu \mathrm{m})$ in the context of AM. The study focused on time- and wavelength-dependent absorption characteristics of selected metals, carbides, oxides and polymers. In the field of polymers, Laumer et al. (Ref 7-10) conducted optical characterization using integrating spheres and two different laser sources, while Heinl et al. (Ref 11) assessed the influence of powder layer thickness on optical properties. Ceramic powder materials were analyzed by Hagedorn in his dissertation, who found differ- 
ences in absorptivity depending on wavelength, material condition (e.g., powdery or solid) and measurement technique used (spectroscopy or integrating spheres) (Ref 12). In a similar context, the absorptivity of various ceramic materials (doped and undoped aluminum oxides) was measured with a pulsed green laser source together with a single integrating sphere by Florio et al. The study describes the absorption-enhancing effect of doping by an effective reduction of both reflectance and transmittance values (Ref 13). This wide range of available system technologies (laser sources, integrating spheres, spectrometers, etc.) and AM-relevant powder materials amplifies the importance of optical properties to the respective manufacturing technique, its process characteristics and the finally achievable part properties.

The optical behavior of a material during its interaction with a light source of a certain wavelength (e.g., laser, broadband source) can be characterized by its absorptance $A$, reflectance $R$ and transmittance $T$, which can be determined experimentally by means of one or more integrating spheres with attached sensor devices. While a single-sphere-system requires several separate measurements of one sample, two spheres with an intervening sample allow the simultaneous retrieval of the observables $R$ and $T$. The latter method, which was employed throughout this contribution, further allows the application of an external stimulus to the sample (e. g. temperature variation) during optical measurements (Ref 14). Due to the law of energy conservation, the sum of $R, T$ and $A$ equals 1 , facilitating the straightforward retrieval of $A$ from $R$ and $T$ measurements $(A=1-R-T)(\operatorname{Ref} 4)$. As will be illustrated in Sect. 2, the observables $R$ and $T$ can further be subdivided into diffuse and unscattered amounts, yielding valuable insights into underlying processes such as multiple scattering (Ref 14-16). However, scattering phenomena in the context of PBF-LB/P have generally been studied rarely, despite inherently occurring on multiple scales due to the ratio of wavelength $(\lambda=10.6 \mu \mathrm{m})$ to the size of possible scattering structures: While the micronsized powder particles lead to Mie scattering ( $\lambda \approx$ object size), smaller intraparticular structures such as spherulites or lamellae could facilitate other superposing effects such as Rayleigh scattering $(\lambda>>$ object size) (Ref 17-20).

Furthermore, since many powder manufacturers modify their materials for enhanced processibility (e.g., better powder flowability, higher optical absorptance) or improved part properties (e.g., increased stiffness, higher wear resistance, better surface quality), effects of such additives on the process behavior must also be considered. A variety of characterization techniques such as differential scanning calorimetry (DSC), scanning electron microscopy, spectroscopic analysis or laser light diffraction is employed to study relevant powder properties (e.g., particle morphology, chemistry, microstructure) (Ref 21). However, transferability and relevance of some of these common methods to the PBF-LB/P process are debatable. Hence, there is still a need for more suitable techniques that resemble the $\mathrm{PBF}-\mathrm{LB} / \mathrm{P}$ process closely enough for adequate powder characterization.

For a deeper understanding of the PBF-LB/P process, detailed analysis of the absorption characteristics is required. The optical material properties need to be correlated with underlying material properties (e.g., chemistry, additives) and to process settings such as the preheating temperature. From that, material-specific and improved energy deposition strategies can be derived, finally enabling the manufacture of parts with increased interlayer adhesion, fewer pores and better mechanical properties.

For this work, a previously employed measurement system based on two integrating spheres (Ref 7-11, 15) was equipped with a suitable hot stage for heating and cooling of the sample during analysis. This measurement system was used for the retrieval of thermo-optical material properties of different commercial powders, thus giving valuable insights into the beam-matter interaction relevant for PBF-LB/P.

\section{Materials and Methods}

\subsection{Measurement System}

A schematic sketch and a photograph of the employed measurement system for temperature-dependent analysis of optical material properties are shown in Fig. 1.

The insides of both spheres are covered with a diffusively reflecting gold coating and all sphere ports for beam entrance and detection are positioned in accordance with DIN 5036-3. For powder characterization as close as possible to the real $\mathrm{PBF}-\mathrm{LB} / \mathrm{P}$ process conditions, the beam of a $\mathrm{CO}_{2}$ laser source (firestar-v20, Synrad, USA) together with a customized hot stage (FTIR-600, Linkam Scientific Instruments LTD., the UK) was used. All reflective optics used for beam guidance are gold mirrors for minimal light losses.

While the bottom port of the transmission sphere is sealed for measurement of total reflectance $R$ and total transmittance $T$, it is opened if the separation of $T$ into diffuse $\left(T_{\text {diff }}\right)$ and unscattered $\left(T_{\text {unsc }}\right)$ transmittance is to be obtained (see Fig. 1). In the case of a sealed bottom port, $T$ is detected at the side port of the transmission sphere. Since the employed high-sensitivity broadband thermopile sensors are sensitive to varying conditions inside the laboratory, longpass filters (5\% cut-on at $8938 \mathrm{~nm}, 50 \%$ cut-on at $9240 \mathrm{~nm}$ ) were placed directly in front of all sensors to minimize power fluctuations.

For accurate, stable temperature control up to $600{ }^{\circ} \mathrm{C}$, the implemented hot stage features a silver heating block with a conical bore for transmission and a Pt100 temperature sensor. All optical elements of the hot stage, i. e. bottom and lid windows as well as the slides for sample placement, are made of infrared (IR) transparent barium fluoride $\left(\mathrm{BaF}_{2}\right)$. This material was selected due to its excellent optical properties (high transmittance and low reflective losses at $10.6 \mu \mathrm{m}$ ), hazard-free application (in contrast to e. g. zinc selenide) and robustness against atmospheric humidity (compared to e. g. sodium chloride).

\subsection{Thermo-Optical Characterization Procedure}

Reference measurements were performed prior to sample analysis using a diffusive gold reflectance standard and the empty hot stage (including all $\mathrm{BaF}_{2}$ windows) for referencing the top and the bottom sphere, respectively. Herein, also the influence of the hot stage on the optical measurements was quantitatively determined and taken into account during subsequent sample testing.

Powder layers of different thicknesses were coated directly onto the $\mathrm{BaF}_{2}$ slide using an adjustable film applicator. The thickness values $(d)$ were selected to analyze process-relevant $(200 \mu \mathrm{m})$, intermediate $(500 \mu \mathrm{m})$ and optically thick $(800 \mu \mathrm{m})$ powder layers. The samples were placed inside the hot stage, 


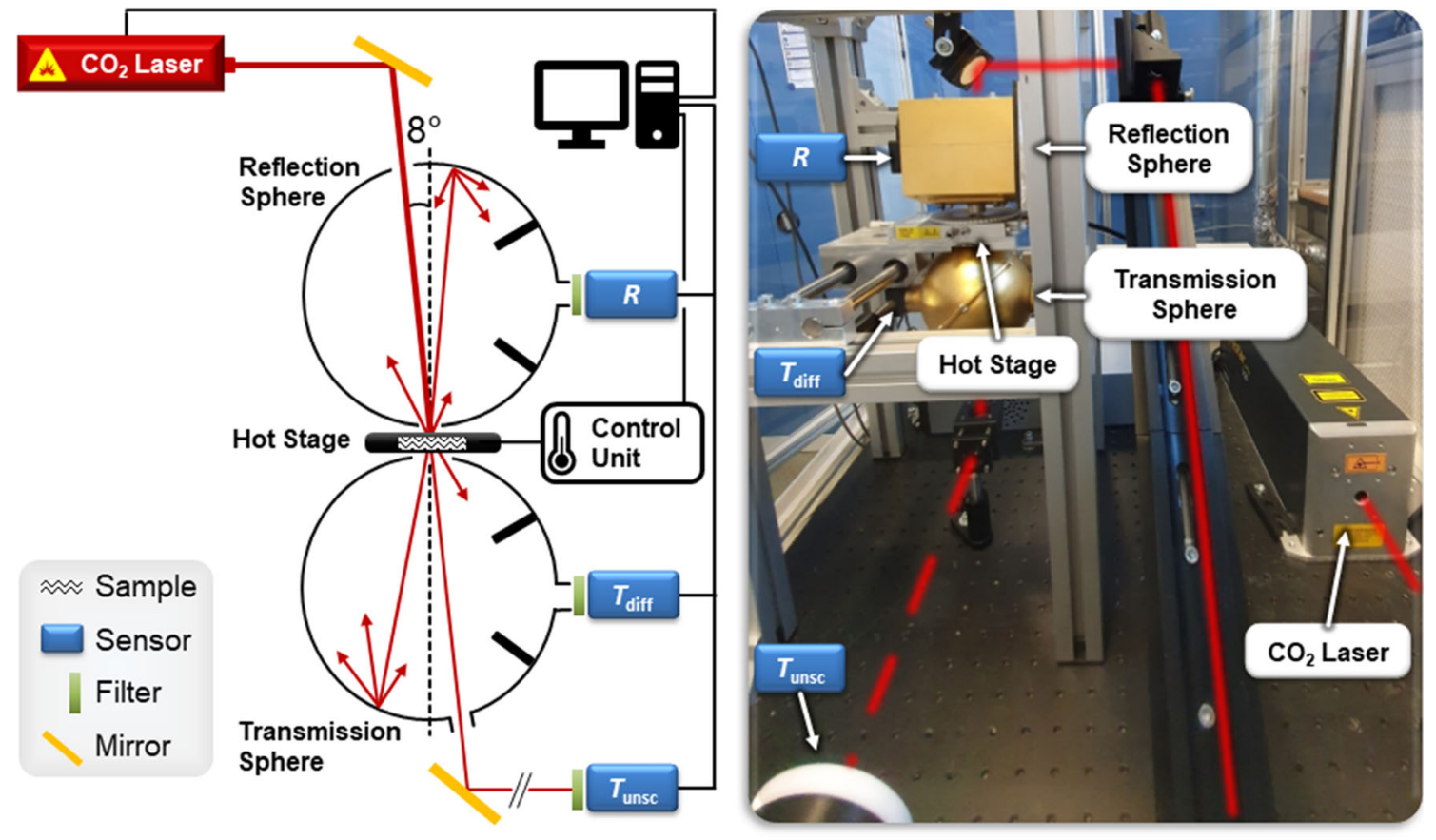

Fig. 1. Double-integrating-sphere system with intervening hot stage for thermo-optical material characterization (left: sketch, right: photograph with schematically shown beam path)

and the temperature was increased continuously until the desired measurement temperature was reached. During optical measurement, the temperature was kept constant. This process was repeated for several target temperatures until the material was fully melted. The measurements during the cooling cycle from the melted state were performed similarly. Heating and cooling rates were $5 \mathrm{~K} / \mathrm{min}$ in all cases.

As the optical measurements were conducted by means of a laser beam, laser-induced material changes needed to be prevented since these would in turn result in altered material properties (e. g. absorption characteristics). Hence, a low laser power of $1.6 \mathrm{~W}$ and a short irradiation time of $1 \mathrm{~s}$ were used throughout all experiments (including referencing procedure).

The acquired sensor data of the sample and reference measurements were further processed to obtain the optical values: (total) reflectance $R$, (total) transmittance $T$, diffuse transmittance $T_{\text {diff }}$, unscattered transmittance $T_{\text {unsc }}$ and absorptance $A$. Every measurement was performed at least 5 times for statistical reasons. Mean values were calculated and measurement uncertainties were determined via error propagation.

\subsection{Powder Materials}

For analysis of material-related effects on the optical behavior, the characterization was performed using various commercially available PBF-LB/P powder materials, all of which had been obtained from EOS GmbH, Germany. A widely studied and industrially used polyamide 12 (PA12) powder (PA 2200) was used as a benchmark. To analyze the influence of additives on the optical behavior, pigment-filled (PA 2202 black) and glass-bead-filled (PA 3200 GF) PA12 powders were also characterized. Moreover, unfilled PA11 (PA 1101) was analyzed to enable the comparison between two different, unfilled base materials, i.e., PA11 and PA12.

Particle size distributions of the PA12 powders were identical with mean particle sizes $\left(d_{50}\right)$ around $40 \mu \mathrm{m}$, while generally smaller particles are present in the PA11 powder $\left(d_{50}=19.3 \mu \mathrm{m}\right)$. Prior to optical analysis, standard DSC measurements were performed for each material to identify suitable temperature ranges between room temperature and the melting region. All powders were characterized in their asreceived state without further modification.

\section{Results and Discussion}

\subsection{Thermo-Optical Properties of Unfilled Polyamide Powders with Varying Layer Height}

For comparison of two different base materials, the temperature-dependent optical properties $(R, T, A)$ of unfilled PA 2200 and PA 1101 with varying layer height are summarized in Fig. 2.

As shown in Fig. 2, the absorptance values in the powdery state of PA 2200 and PA 1101, which are key parameters for powder qualification for the $\mathrm{PBF}-\mathrm{LB} / \mathrm{P}$ process, are similarly high for both materials with maximum values around $90 \%$ in the case of thick powder layers $(d \geq 500 \mu \mathrm{m})$. The reflective behavior of both materials is roughly independent of temperature and does not change with varying layer height. In all cases, the values of $R$ remain in the same order of magnitude with mean values ranging in a narrow interval between 5.4 and $6.9 \%$. The results for PA 2200 can be confirmed by findings in the literature (Ref 11, 15), where similar integrating-sphere setups had been used. In general, no clear difference in reflective behavior between both powders can be recognized, which essentially means that during PBF-LB/P, the same amount of laser radiation is lost to reflection and therefore not available for melting of the powder.

Unlike the reflection properties, the transmittance values strongly correlate with the phase transitions occurring around 


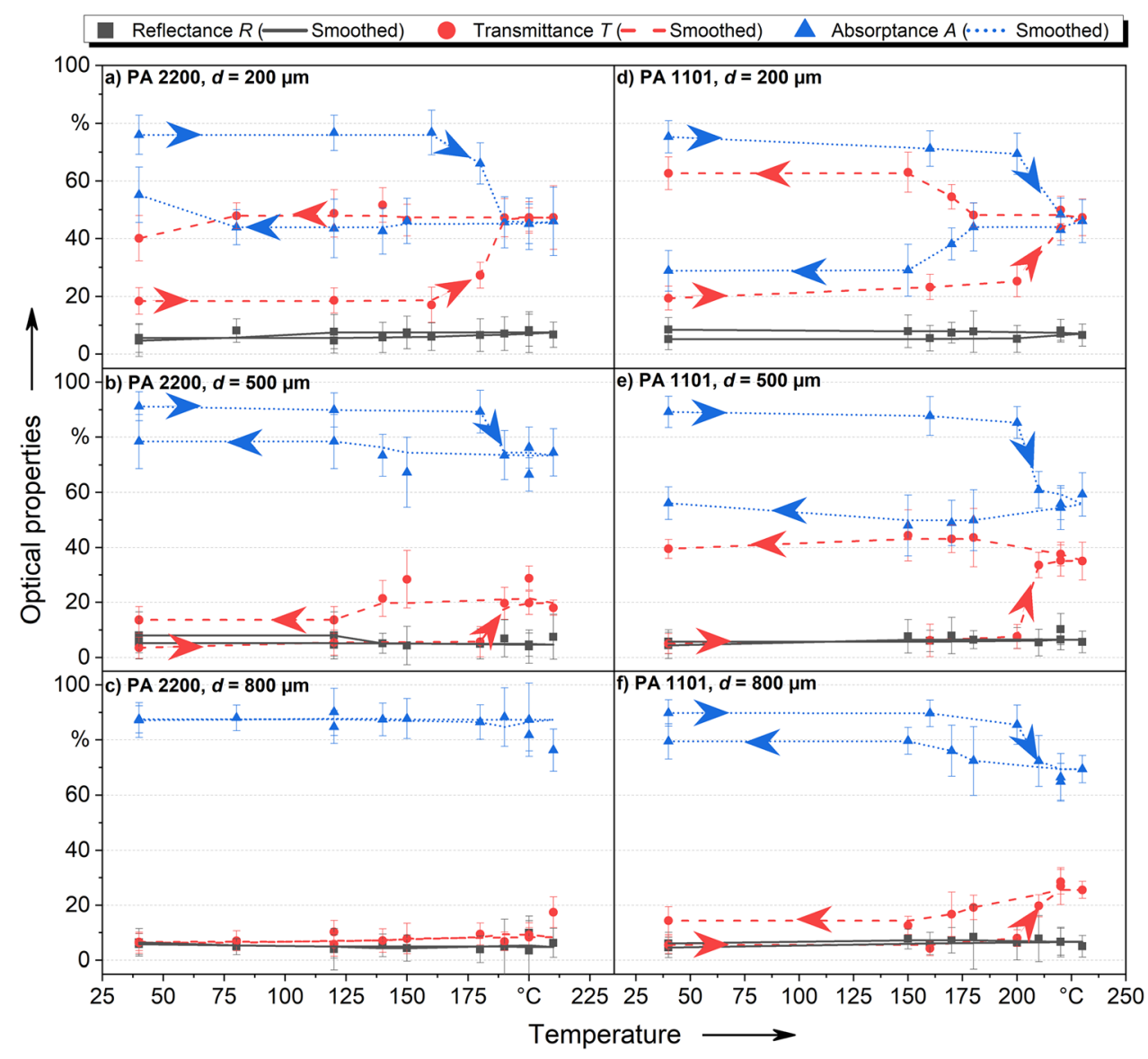

Fig. 2. Temperature-dependent optical properties $(R, T, A)$ of unfilled PA $2200(\mathrm{a}-\mathrm{c})$ and PA 1101 (d-f) with varying layer height. Mean values and uncertainties are shown by data points and error bars, respectively. Arrows indicate heating and cooling

the respective melting temperatures of $185^{\circ} \mathrm{C}(\mathrm{PA} 2200)$ and $201{ }^{\circ} \mathrm{C}$ (PA 1101). As the melting is initiated, the particles begin to soften and form necks to adjacent particles. Continuous heating leads to the melting of the particle cores until a homogeneous polymer melt is generated (c.f. Ref 22). This liquid phase growth hence includes the elimination of particleair interfaces and the melting of crystalline structures inside the particles, leading to a measurable, significant increase in transmittance. Accordingly, the absorptance drops at the transition from powdery to molten state. In general, this effect is most pronounced for the thinnest layers since these are especially translucent for the laser beam. As depicted in Fig. 2, PA 1101 exhibits a more pronounced increase in transmittance than PA 2200 for all layer heights. For the actual PBF-LB/P process, this melting-induced increase in transmittance could result in a higher penetration depth of the laser beam, allowing the IR radiation to reach deeper layers for energy deposition. This may imply beneficial effects such as stronger interlayer bonding and therefore enhanced mechanical properties along the building direction.

Subsequent cooling leads to the crystallization and solidification of the polymeric films, with no clear trend visible in the evolution of the optical properties. This may be attributed to the complex superposition of several mechanisms during cooling: Initial spherulite nucleation results in the formation of possible scattering centers (Rayleigh) for the incident laser radiation. During crystal growth, the interface between amorphous polymer and crystalline spherulites increases, which effectively increases scattering (Mie). However, as the crystals continue to grow, they start to impinge on each other, reducing the interfacial scattering again (c.f. Ref 23). Furthermore, scattering may occur isotropically (evenly in all directions) or anisotropically (in a preferred direction), i. e. it can generally increase or decrease transmittance. Therefore, a clear effect of crystallization and solidification on the optical behavior of the polymer cannot be deduced from the depicted results.

In general, the particle-related impact on the optical properties (observed during heating) is distinctively more pronounced than the effect of the crystallization during cooling.

\subsection{Influence of Powder Additives and Process Temperature on the Optical Behavior}

The influence of commonly used additives (carbon black, glass beads) and temperature on the optical properties is depicted in Fig. 3. Here, two temperatures were selected for the assessment: the lowest temperature at which the measurements were conducted $\left(40{ }^{\circ} \mathrm{C}\right)$ and the material-specific preheating temperature (deduced from DSC testing). As the latter is the actual processing temperature during $\mathrm{PBF}-\mathrm{LB} / \mathrm{P}$, it can be considered the most relevant temperature for determining the suitability of a powder with regard to its optical behavior.

As shown in Fig. 3, the reflective behavior is neither affected by temperature, nor by additivation, nor by polymer chemistry, with mean $R$ values around $5.7 \%$. All powders exhibit mean absorptances between 70 and $85 \%$, with 


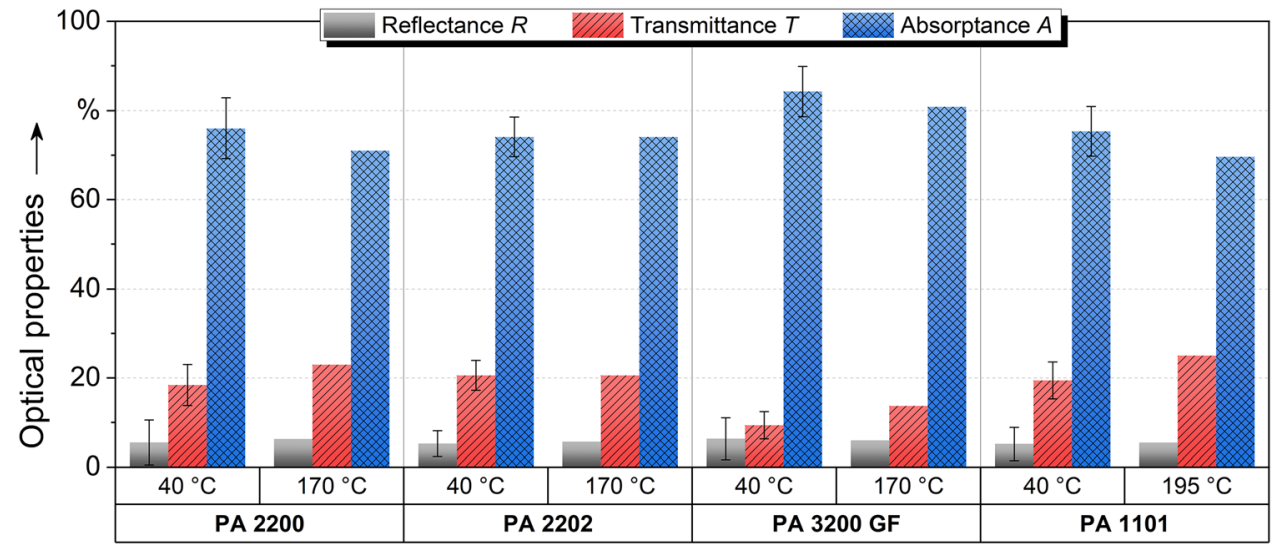

Fig. 3. Optical properties $(R, T, A)$ of powder layers $(d=200 \mu \mathrm{m})$ of unfilled PA 2200, pigment-filled PA 2202, glass-bead-filled PA 3200 GF and unfilled PA 1101 at $40{ }^{\circ} \mathrm{C}$ and at the material-specific preheating temperature. Mean values and uncertainties are shown by columns and error bars, respectively. Note that the values at the preheating temperatures were derived from the smoothed data, and thus, no uncertainties are included

PA 3200 GF showing the highest value of $84.2 \pm 5.6 \%$ at $40{ }^{\circ} \mathrm{C}$. Since all powders exhibit optical properties quite similar to those of the benchmark PA 2200, principal processability regarding the energy deposition process during $\mathrm{PBF}-\mathrm{LB} / \mathrm{P}$ can be expected for these powder systems.

Comparing PA 2200 and PA 2202 in Fig. 3, it seems that the addition of carbon black has no significant effect on the optical behavior of the powder at a wavelength of $10.6 \mu \mathrm{m}$. However, the addition of glass beads (PA $3200 \mathrm{GF}$ ) leads to an increased absorptance compared to the unfilled powder, which can be attributed to two possible effects: the high inherent absorptance of glass in the far IR spectral range or the increased multiple scattering due to different refractive indices of the glass and the polymer (Ref 24). Thus, adding glass fillers not only leads to enhanced mechanical properties of the resulting parts, but may also reduce the amount of radiative energy required during the $\mathrm{PBF}-\mathrm{LB} / \mathrm{P}$ process.

Despite their slightly different chemical compositions, both unfilled powders PA 2200 and PA 1101 interact with the laser radiation in the same way at the considered temperatures, showing the same values of $R, T$ and $A$. This may be attributed to the similar molecular structure of these polyamides, with only one additional carbon atom in the methylene chain of PA12 compared to PA11. Therefore, similar vibrational modes of the PA11 and PA12 molecules may be induced at the wavelength of $10.6 \mu \mathrm{m}$, resulting in the same optical behavior (c.f. Ref 25). Fourier transform IR spectroscopic investigations on PA11 and PA12 tubular films, where the influence of varying powder properties is eliminated, confirm the identical optical behavior of both materials around a wavenumber of $943 \mathrm{~cm}^{-1}$ (i.e., $\lambda=10.6 \mu \mathrm{m}$ ) (c.f. Ref 26). Nevertheless, other differences or similarities with regard to the bulk powder properties (e.g., particle sizes, morphology) may also play an important role in the fundamental beam-matter interaction. Furthermore, at $170{ }^{\circ} \mathrm{C}$, their transmittance is increased compared to the values at low temperature. This behavior is also observed in PA $3200 \mathrm{GF}$, whereas only PA 2202 exhibits equal $T$ values at both temperatures. This suggests that the addition of carbon black suppresses this effect, essentially keeping the optical properties temperature-independent as long as no phase change is induced. Hence, characterization at room temperature may be sufficient for powder qualification of pigment-filled (black) systems, whereas for other filled and non-filled (white) powders, temperature-dependent characterization may yield more process-relevant insights.

\subsection{Correlation of Scattering Processes and Material Properties During the Beam-Matter Interaction}

To gain insights into scattering processes during the interaction of the laser beam with unfilled and pigment-filled PA12 powder, the total transmittance is experimentally separated into diffuse and unscattered amounts (see Fig. 4).

During heating, almost no unscattered transmission through the powder layers occurs. This can be attributed to the particleair interfaces present in the powdery state of the material that act as scattering centers for the incoming radiation (Ref 15,18 ) and thus only allow diffuse transmission. Due to the transition from solid powder to liquid polymer, i. e. the coalescence of the particles to a homogeneous melted film, the values of $T_{\text {unsc }}$ increase in the melting region $\left(175-210{ }^{\circ} \mathrm{C}\right)$ and maintain a certain increased level throughout subsequent cooling. Similar to the findings in

Section 3.1, no definitive effect of crystallization and solidification on the optical behavior can be derived from these data.

Most interestingly, the melting-induced increase in $T_{\text {unsc }}$ is significantly less pronounced in PA 2202 (Fig. 4b and d) than in PA 2200 (Fig. 4a and c). Accordingly, during and after melting, the measured total transmittance $T$ consists to a greater extent of $T_{\text {diff }}$ in the case of PA 2202 compared to PA 2200. As the only difference between these cases is the added pigment in PA 2202 (i. e. same base material and sample condition due to the same temperature history), the mainly diffuse propagation of the laser radiation through this material is the result of the added carbon black.

Such additive-related scattering effects could possibly have process implications such as different energy distributions inside the powder bed which could in turn lead to decreased geometrical accuracy of part contours and/or lacking interlayer adhesion. This would hence require the adaption of the employed irradiation strategy (e.g., hatching strategy) for ideal energy deposition, sufficient melting and optimal part properties. 


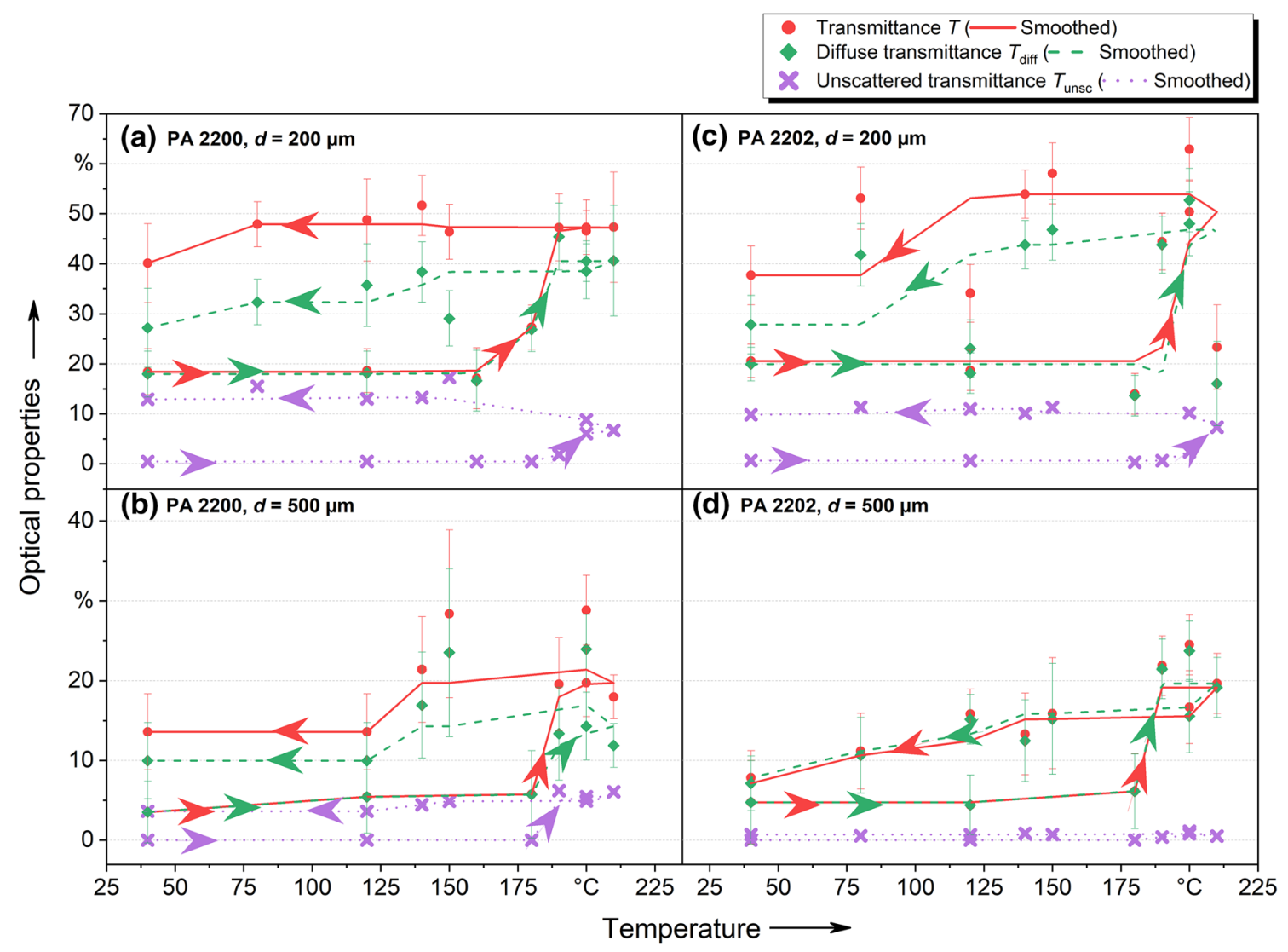

Fig. 4. Temperature-dependent optical properties ( $\left.T, T_{\text {diff, }} T_{\text {unsc }}\right)$ of unfilled PA 2200 (a, b) and pigment-filled PA 2202 (c, d) for layer heights of $200 \mu \mathrm{m}$ and $500 \mu \mathrm{m}$. Mean values and uncertainties are shown by data points and error bars, respectively. Arrows indicate heating and cooling. Note that uncertainties in the case of $T_{\text {unse }}$ are too low to display (uncertainty values $<0.015 \%$ )

\section{Conclusion}

An extended measurement system consisting essentially of two integrating spheres, a $\mathrm{CO}_{2}$ laser source, and a hot stage for sample heating and cooling was described and used for the temperature-dependent, simultaneous retrieval of reflective and transmissive material properties in the context of powder-based AM. To highlight the suitability of the described system, several relevant and commercially available polymer powders were characterized. As shown by the experimental results, differences between pure polyamide powders as well as influences of additives and temperature on the optical behavior can be determined by this approach.

Measured reflective losses were generally low in all cases with reflectance values below $10 \%$, which remained unaffected by varying base material, layer height, temperature (including phase transitions) and added fillers (pigment, glass beads). While the melting of the material was clearly observed by a distinct increase in transmittance (and therefore reduction in absorptance) due to decreased multiple scattering, crystallization involves the complex superposition of several microscopic mechanisms, thus impeding the detection of systematic effects on the optical behavior during the solidification phase. Differences as well as similarities in optical behavior between different base materials, namely unfilled PA11 and unfilled PA12 powders, were found and confirmed by findings in the literature. In addition to the effects of additives and preheating temperature on the absorption characteristics, the separation of transmitted laser light into diffuse and unscattered amounts yielded further insights into process-relevant scattering effects. Here, a pronounced diffuse propagation of the laser beam through the pigment-filled, molten polymer was observed and attributed to the increased scattering in this system compared to the unfilled material.

The presented findings can serve as a basis for enhanced material processibility, process strategies and resulting part properties. With respect to a better material design, the technique is a valuable tool to identify and systematically test powder modifications required for enhanced processibility (such as appropriate absorption-enhancing agents). For a faster determination of suitable process settings and strategies, the experimental results from reflectance and transmittance measurements may also yield important insights. For instance, strong forward scattering indicates an increased penetration depth of the laser beam, which in turn may require the adaption of the powder layer thickness and/or energy density during PBF-LB/P. Thus, better part quality in terms of complete melting and reduced porosity can be achieved, resulting in mechanically improved components. In the case of mainly diffuse transmittance (without pronounced collimated transmittance), on the other hands, a modification of the irradiation strategy (e.g., hatching pattern, contour irradiation) may be necessary to minimize geometrical deviations from the desired part dimensions. In summary, the presented characterization technique is a suitable, fast method for powder qualification and for the estimation of necessary process adaptions (e.g., reduction or increase in energy density). Besides, its potential 
for a time-efficient definition of process parameters and strategies, the method can also be beneficial during early stages of powder development, where fast feedback loops can be realized to optimize the optical material behavior without the need to conduct complete building jobs. Future studies using lower wavelengths could facilitate the detailed investigation of crystallization-related scattering effects due to a higher achievable resolution than in the case of the $\mathrm{CO}_{2}$ laser. The ability to determine the impact of different microscopic aspects (e.g., crystallinity, spherulite size) would enable for instance the investigation of powder aging on the energy deposition during PBF-LB/P.

\section{Acknowledgments}

The authors gratefully acknowledge funding of the Collaborative Research Center 814 (CRC 814), sub-project A3 and of the Erlangen Graduate School in Advanced Optical Technologies (SAOT) by the German Research Foundation (DFG) in the framework of the German excellence initiative. We further thank Monika Gessler from EOS GmbH for the supply of PA $3200 \mathrm{GF}$ powder for this study.

\section{Open Access}

This article is licensed under a Creative Commons Attribution 4.0 International License, which permits use, sharing, adaptation, distribution and reproduction in any medium or format, as long as you give appropriate credit to the original author(s) and the source, provide a link to the Creative Commons licence, and indicate if changes were made. The images or other third party material in this article are included in the article's Creative Commons licence, unless indicated otherwise in a credit line to the material. If material is not included in the article's Creative Commons licence and your intended use is not permitted by statutory regulation or exceeds the permitted use, you will need to obtain permission directly from the copyright holder. To view a copy of this licence, visit http://creativecommons.org/licenses/by/4.0/.

\section{References}

1. I. Gibson and D. Shi, Material properties and fabrication parameters in selective laser sintering process, Rapid Prototyp. J., 1997, 3(4), p 129 136

2. N.K. Tolochko, Y.V. Khlopkov, S.E. Mozzharov, M.B. Ignatiev, T. Laoui and V.I. Titov, Absorptance of powder materials suitable for laser sintering, IEEE Rapid Prototyp. J., 2000, 6(3), p 155-161. https://doi. org/10.1108/13552540010337029

3. R.D. Goodridge, C.J. Tuck and R.J.M. Hague, Laser sintering of polyamides and other polymers, Prog. Mater. Sci., 2012, 57(2), p 229267. https://doi.org/10.1016/j.pmatsci.2011.04.001

4. R. Poprawe, Chapter 3 Absorption von Laserstrahlung, Lasertechnik Für Die Fertigung, Springer Berlin Heidelberg New York, 2005, p 1339

5. D.L. Bourell, T.J. Watt, D.K. Leigh and B. Fulcher, Performance limitations in polymer laser sintering, Phys. Procedia, 2014, 56(C), p 147-156. https://doi.org/10.1016/j.phpro.2014.08.157

6. J.P. Kruth, X. Wang, T. Laoui and L. Froyen, Lasers and materials in selective laser sintering, Assem. Autom., 2003, 23(4), p 357-371. h ttps://doi.org/10.1108/01445150310698652

7. T. Laumer, T. Stichel, M. Sachs, P. Amend, and M. Schmidt, Qualification and modification of new polymer powders for laser beam melting using ulbricht spheres, high value advanced research in virtual and rapid prototyping, in Proceedings of the 6th International
Conference on Advanced Research in Virtual and Rapid Prototyping, VR@P 2013, 2013, 1(Laoui 2000), pp. 255-260. https://doi.org/10. 1201/b15961-48

8. T. Laumer, K. Wudy, M. Drexler, P. Amend, S. Roth, D. Drummer and M. Schmidt, Fundamental investigation of laser beam melting of polymers for additive manufacture, J. Laser Appl., 2014, 26(4), p 042003. https://doi.org/10.2351/1.4892848

9. T. Laumer, T. Stichel, T. Bock, P. Amend and M. Schmidt, Characterization of temperature-dependent optical material properties of polymer powders, AIP Conf. Proc., 2015, 2015, p 160001. https://d oi.org/10.1063/1.4918508

10. T. Laumer, T. Stichel, K. Nagulin and M. Schmidt, Optical analysis of polymer powder materials for selective laser sintering, Polym. Test., 2016, 56, p 207-213. https://doi.org/10.1016/j.polymertesting.2016.10.010

11. M. Heinl, T. Laumer, F. Bayer and T. Hausotte, Temperature-dependent optical material properties of polymer powders regarding in-situ measurement techniques in additive manufacturing, Polym. Test., 2018, 71, p 378-383. https://doi.org/10.1016/j.polymertesting.2018.09.016

12. Y. Hagedorn, Additive Manufacturing of High Performance Oxide Ceramics via Selective Laser Melting, Ph.d. thesis (2013)

13. K. Florio, S. Pfeiffer, M. Makowska, N. Casati, F. Verga, T. Graule, H. Van Swygenhoven and K. Wegener, An innovative selective laser melting process for hematite-doped aluminum oxide, Adv. Eng. Mater, 2019, 21(6), p 1801352. https://doi.org/10.1002/adem.201801352

14. J.W. Pickering, C.J.M. Moes, H.J.C.M. Sterenborg, S.A. Prahl and M.J.C. van Gemert, Two integrating spheres with an intervening scattering sample, J. Opt. Soc. Am. A, 1992, 9(4), p 621. https://doi.org/ 10.1364/JOSAA.9.000621

15. T. Schuffenhauer, T. Stichel and M. Schmidt, Experimental determination of scattering processes in the interaction of laser radiation with polyamide 12 powder, Procedia CIRP, 2020, 94, p 85-88

16. J.W. Pickering, S.A. Prahl, N. van Wieringen, J.F. Beek, H.J.C.M. Sterenborg and M.J.C. van Gemert, Double-integrating-sphere system for measuring the optical properties of tissue, Appl. Opt., 1993, 32(4), p 399. https://doi.org/10.1364/AO.32.000399

17. A. Wegner, Theorie Über Die Fortführung von Aufschmelzvorgängen Als Grundvoraussetzung Für Eine Robuste Prozessführung Beim Laser-Sintern von Thermoplasten, Ph.d. thesis (2015)

18. J. Steinberger, Optimierung Des Selektiven-Laser-Sinterns Zur Herstellung von Feingußteilen Für Die Luftfahrtindustrie, Ph.d. thesis (2001)

19. X. Liu, M. Boutaous, and S. Xin, Scattering effect in radiative heat transfer during selective laser sintering of polymers, in AIP Conference on Proceedings (2016), p. 1769

20. X. Liu, Numerical Modeling and Simulation of Selective Laser Sintering in Polymer Powder Bed, Ph.d. thesis (2017)

21. A.T. Sutton, C.S. Kriewall, M.C. Leu and J.W. Newkirk, Powder characterisation techniques and effects of powder characteristics on part properties in powder-bed fusion processes, Virtual Phys. Prototyp., 2017, 12(1), p 3-29

22. U. Ajoku, N. Saleh, N. Hopkinson, R. Hague and P. Erasenthiran, Investigating mechanical anisotropy and end-of-vector effect in lasersintered nylon parts, Proc. Inst. Mech. Eng. Part B J. Eng. Manuf., 2006, 220(7), p 1077-1086

23. G. Lamberti and G. Titomanlio, Interaction between light and crystallizing polymer: a simulation study, Eur. Polym. J., 2005, 41(9), p 2055-2066

24. M. Rubin, Optical properties of soda lime silica glasses, Sol. Energy Mater, 1985, 12(4), p 275-288. https://doi.org/10.1016/0165-1633(8 5) $90052-8$

25. S. Ishii, H. Suzuki, Y. Morisawa, H. Sato, S. Yamamoto, Y. Ozaki, C. Otani, T. Uchiyama, and H. Hoshina Vibrational spectra of nylon-6, nylon-6/6, nylom-11 and nylon-12 studied by Terahertz Spectroscopy, in 2012 37th International Conference on Infrared, Millimeter, and Terahertz Waves (IEEE, 2012), pp. 1-2, https://doi.org/10.1109/IRM MW-THz.2012.6380372

26. S. Rhee and J.L. White, Investigation of structure development in polyamide 11 and polyamide 12 tubular film extrusion, Polym. Eng. Sci., 2002, 42(1), p 134-145. https://doi.org/10.1002/pen.10934

Publisher's Note Springer Nature remains neutral with regard to jurisdictional claims in published maps and institutional affiliations. 